\title{
The Role of Geographic Information Systems (GIS) to Improve Environmental Auditing using Disasters Sample Survey of Auditors in the Iraqi Environment
}

\author{
Zeina Khdier Abass and Ibtihaj Ismaial Yaqoob \\ Department of Accounting, College of Administration and Economics, \\ University of Al-Mustansiriyah, Baghdad, Iraq
}

\begin{abstract}
The aim of this study is to elaborate on the challenge faced on the scrutiny of developments in technical arena and possibility to adopt her in environments plagued by disasters and crises. This is intended to achieve by finding suitable land for a proposed entrance to adopt technical (GIS) in environmental auditing which includes Iraq's environment based on international standards and INTOSAI Standard 5540. The technical (GIS) based on disasters and crises is adopted to regulatory reform in senior regulatory bodies to reduce the waste of resources in accordance with the limited resources available at the current stage in the Iraqi environment. Based on the availability of disasters and crises in the Iraqi environment, this study searched out a sentence of almost conclusions highlighted in the platform and infrastructure to build technical (GIS) in environmental auditing. Also, a statistical analysis was provided using SPSS program by the availability of infrastructure and human and technical capabilities and systems for the study sample as approved by the auditorsing in the office of financial supervision.
\end{abstract}

Key words: Audit Standard 5540, disaster based audit, sanitary wastes, regulatory reform, environmental auditing, supervision

\section{INTRODUCTION}

There has been increase in the challenges faced by the SAIs which includeswidening of environmental problems simply called environmental disasters. This issue has led to the need to develop an audit environment. These environmental problems include the remnants of health-care professionals originating from hospitals, governmental, health and laboratory-all waste related to health.

In the context of disaster and crisis audits, the traditional methods and mechanisms of verification and their supporting tools to obtain effective proof have been established. This has called for an urgent need for the use of scientific techniques and methods that support environmental application that work in accordance with the requirements of the INTOSAI (2013). The scientific techniques employ geospatial information in disaster management audits and address the continuous contribution of role of geospatial information in auditing and how it can be a useful tool in supporting audit work. The two-way disaster risk reduction tool being the focus of this current research and disaster-related audit assistance (direction for future research) are examined for the disaster management activities. With regard to disaster an incident whose history cannot be predicted, it may be natural or human (artificial) or the combination of the two.

One of the most prominent disasters that affect the environment is the solid waste. The adverse effect of that is reflected in the achievement of components of the environment and sustainable development. From this perspective, the environmental performance has reported suffering from the gaps and weaknesses submitted by the SAIs in many countries. The reflection on the low quality of the evidence obtained by the auditor is the basis of the lack of reliable database. In the 4th meeting in Tunis, the Environment Task Force of the Arab Organization for Supreme Audit and Financial Institutions (ARABOSAI) confirmed that one of the most important challenges of the SAIs in the field of environment is the lack of a database adopted by the SAIs and control of solid waste.

This study aimed to promote the environmental auditing on the basis of disasters using Geographic Information Systems (GIS) to improve environmental auditing and the adoption of increasing the effectiveness of environmental performance reports. Through the

Corresponding Author: Zeina Khdier Abass, Department of Accounting, College of Administration and Economics, University of Al-Mustansiriyah, Baghdada, Iraq 
questionnaire, statistical analysis as done and evidence was derived from the ground in the Iraqi environment. Possession of the qualifications and main components of the technical use of the audit work are directed for the auditors (financial censors) working in the Federal Audit Bureauas the body responsible for environmental auditing. Taking consideration of that they are regarded as one of the most important environmental disasters affecting the Iraqi environment at the current stage and form of the health.

The adverse effect of the high percentage of environmental pollution resulting from public and private hospitals led to the motivation of the study. The reports from the Ministry of Environment and the Federal Financial Control Bureau confirm the catastrophic situation due to the lack of reports of the environmental audit issued accordingly by the Federal and Financial Control Bureau on the health sector on solid waste and their location. By raising the following research questions, the research problem was presented:

- Is the integration of technical developments as a GIS system into disaster-based environmental auditing contributes to the performance of the environmental audit team?

- Are there any impediments to using this technique by the auditors in the Iraqi environment?

The main objective is to examine the challenges facing the higher auditing bodies from developments in the technical arena and the possibility of adopting those techniques in environments that suffer from disasters such as the Iraqi environment. By looking for the suitable ground for the proposed GIS approach, the adoption is in accordance with the international standards of INTOSAI which includes ISSAI 5540 Standard. This is in terms of human and technical potential of GIS in environmental auditing and the existence of supporting elements.

Achieving the requirements of the reform of the ecosystems and their conformity with the contemporary methods as stemmedfrom the combination of academic, research and technical visions is the importance of this research, thus, adopted by the supreme governmental supervisory bodies. The hypothesis of this study is as follow: "Environmental auditing under the GIS system contributes to the improvement of environmental audit reports"

Literature review: The GIS and environmental auditing system are the two variables that are separately discussed in this study as follows:
Ivanova and Yankov studied the "Application of Geographic Information Systems in Crisis Management" with the aim to highlight the main features and objectives of the crisis management. The most important of which is the preparation of clear and quick information. The study provides solutions to end or control the crisis by adopting Geographic Information Systems (GIS) through remote sensing to monitor some environmental issues such as: monitoring desertification and forest fires. The study concluded that through the availability of satellites and geography, the GIS contributes to crisis management and protection.

Furthermore, Hovitelal studied the introduction to enhanced decision-making in crisis management based on Voluntary Geographic Information systems (VGI) and Decision Support Systems (DSS) as published in proceedings of the International Conference (ISCRAM) in Germany. This study is based on the issues surrounding the cause of events in Japan in 2012 and the United States of America in 2011 where it is advised that a measure should be taken to increase the capacity of communities to hedge, adapt and prepare for disasters.

By providing citizens with voluntary information from their geographical locations, the study aimed at community participation through their mobile phones as an important source of support for decision-making systems. The study finally found that the decision support systems and the integration of voluntary GIS contributes by providing a voluntary community-based information base (VGI) to decision-making in response to crises.

A working paper on "The Role of Third-country Effect of Geographical Information on International Banks" was presented by Fotopoulos and Louvi to the Economic Research Department of the Bank of Greece/Athens. The aim of the study is to explain the impact of geographic information systems on the international phenomenonin terms of providing information on financial crises for the international banks. The adoption and organization of geographic information and financial information in the prediction of financial crises are the most important results of the study as financial crises move from one environment to another.

Through some Arab literature reviews, the interest of literature was reflected in the GIS system as follows: the study of Jacob on "The leading role of the GIS system in improving the disaster-based auditing in the Iraqi environment" was published in Al-Muthanna Journal of Administrative and Economic Sciences from the Third Annual Arab Accounting Conference. By proposing a portal for environmental auditing based on disasters in 
the Iraqi environment, the study aimed to examine the present technology of GIS in environmental auditing. The most important findings of the study is the introduction of environmental auditing on the basis of disasters while an approach was proposed on the availability of a number of pillars which can be adopted and relied upon.

The economic role of external auditing in the field of solid waste management to achieve sustainable development was investigated by Shaheen. The aim of the study is to analyze the solid waste management system and its impact on achieving sustainable development by highlighting the role of the higher regulatory bodies and accounting in the field of environmental auditing. By reviewing the activities related to solid waste management in the Arab Republic of Egypt, the study presents a theoretical framework for the use of GIS.

The most important results showed that there is possibility of completing the review tasks at the stage of planning the work by reviewing the solid waste management system using GIS and GPS. The most important information related to the factors that affect solid waste management during its stages is also studied. The result also showed the multiplicity of performance effects as relied upon by the auditor to judge the achievement of economy with effectiveness and efficiency in the management of solid waste.

Furthermore, Abu al-Maati and Yusuf reported on the impact of the integration of the GIS system and operational sectors on the efficiency of decision-making in times of crises and disasters in the light of IFRS8. The study aimed to enumerate the impact of integration between geographic information systems and operational sectorsand its impact on the efficiency of decision making in times of crisis and disaster.

The integration between GIS and the operational sectors while minimizing the effects of crises and disasters by dividing the organization into operational sectors and identifying the revenues and expenses of each sector to provide accurate information in accordance with IFRS 8 is the most important results of the study.

In crisis management, previous studies suggest the use of geographic information systems technology towards the enhancement of information while the research theorization did not address the application of any of the research to enhance the results according to the Arab literatures.

Therefore, the present study elaborated on the GIS system in terms of its use in environmental auditing to enhance the work of the higher governmental supervisory bodies following the requirements of the ISSI 5540 Standard. Also, the opinion of the sample of auditors working at the Federal Audit Bureau to explore the possibility of applying GIS through the availability of its basic components was examined.

\section{Disaster-based environmental audit using GIS}

The concept of environmental auditing: In accordance with Standard 1911, the audit is known as an independent and documented systematic process to obtain an audit evidence of records, information and other facts relating to the policies, procedures or requirements as presented through the audit criteria.

According to EPA, environmental auditing is defined as an objective and documented periodic assessment of unit operations compared to environmental auditing standards. Environmental auditing can investigate highrisk areas of business and detailed assessment of all ongoing operations in the unit as believed by the American Institute of Certified Public Accountants (AICPA). Additionally, according to AICPA, the extent to which existing laws and regulations are in compliance and strengthening compliance with industry standards and improving management awareness of environmental issues in the development of operational processes and environmental uses are highlighted.

Under the Supreme Audit Organization (INTOSAI), the environmental monitoring has shown that environmental monitoring does not differ significantly from the normal control exercised by the SAIs. INTOSAI (2001) added that it is possible to include environmental control in financial control (the results of the third questionnaire on environmental control).

Geographic Information System (GIS) and its uses: Since, the late 1970's, Geographic Information Systems (GIS) has become increasingly important and has expanded its use in several fields. In many organizations, this is one of the most widely used computer systems. It is an important source for providing information such as: maps, images, numbers and other technologies.

Computation is as follow (www/http.geo-phd-org): It is not dealt with at the level of individuals but rather at the level of the departments and institutionsas it deals with a huge amount of information through their spatial position which in addition gives a clear picture of the distribution of reality to dealing with numbers and maps, texts and images concurrently.

There is potential to organize information in the form of layers as required. Performance of various treatments and efficient in addition with analysis processes to the stage of making appropriate and rapid decisions. As satellite data (GIS system) consists of several components 
which includes physical and the electronic calculator of full capacity (Full Cash) global positioning devices, scanner devices and the nature of color and ordinary color, then, it can deal with the any available data. The software system includes data systems, geographic information, satellite data, maps, tabular data and documents and the human resources which is preferred to have knowledge and experience in the use of computer and GIS.

Role of the GIS system in improving the work of the supreme audit institutions: The International Organization of Supreme Audit Institutions (ITSAI) was prompted to use the GIS in environmental auditing for crisis and disaster management to issue the International Standard for Supreme Audit Institutions (ISSAI5540) by the Working Group on Disaster Assistance and Audit (WGAADA). The ISSAI5540 highlighted the increasing importance of the role that GIS can play in auditing. It also, highlighted how it can be useful tool in supporting the environmental audit work on disaster management activities.

As described in the 5540 standard below, the ISSAI5540 which is concerned with use of GIS information demonstrates the added value that can be derived from the use of the information resulting from the technology in the planning, design, risk assessment, analysis and final report (INTOSAI., 2013).

Due to the risk information it provides to decide on the objectives and scope of the audit and to guide the control teams to manage the overlapping of the subject being assessed, GIS information is used in the design phase of the audit. Instead of the traditional methods to be converted to sampling according to satellite images, this will be reflected in the approach to be adopted by the audit team. Similarly, it can be used by the Ministry of Health and Environment or the General Authority for air and seismic monitoring in the Iraqi environment.

Following the stage of designing important activities and decision-making regarding the quality and quantity of data collected and the source of the spatial quality of information.

Awareness on the amount of geographical information available to the auditor on the public and the geographical information available in the concerned departments and institutions (such as the Ministry of Health and the Environment in Iraq). The devices of the Global Positioning System (GPS) and GPS receivers can be used for the awareness. Accordingly, the field data can be analyzed not only in subsequent stages but can be done immediately when the audit team uses GPS and satellite maps to link the field data to its geographical location and when the coordinates are entered into a device program called global positioning system besides maps. Thus, the field data are drawn directly and clearly, so that, important questions regarding field observations can be drawn.

It is possible to ask the spatial questions that are related to multiple data layers with the existence of Geographic Information Systems (GIS) through the use of geographic location information like in the case of the medical and laboratory waste incinerators which is located near residential areas of Baghdad city.

When comparing the presentation in words only, the results of the audits such as mapping the geographic information on the map will provide added-value to the reports and more transparency to the audience. The list of the use of technical data (GIS) in the auditor is included in the Standard 5540 as follow (INTOSAI., 2013):

- What geographical information is necessary to answer audit inquiries?

- What is the accurate value required for geospatial data?

- What time frame is required for geospatial data?

- What spatial data are available?

- What is the quality of available geospatial data?

- From which source were geospatial data derived and what is their degree of credibility?

- What are the available geospatial data costs if they cannot be assembled as part of the audit process?

- Are the auditors involved in the audit process of the knowledge necessary to collect and analyze geospatial information data and to seek the assistance of external experts?

Scientific and practical requirements for the auditor to use the system (GIS): It is necessary to have a system of special qualifications in order to be able to use the GIS information effectively and efficiently by the auditor. The auditors need not additional educational qualification. In accordance with the requirements of the Santosi Standard (5540), the auditors need to possess certain qualifications such as awareness, skills and open-mindedness.

Qualifications of the auditor under the use of GIS awareness on:

- Awareness is necessary in dealing with huge amount of data in spatial geography

- Disaster risk according to geographical distribution model

- How organization deals with disaster risk

- The quality of the spatial geographical data used in the audit

- Temporal distances in the use of geospatial information 
Skills in:

- The use of GIS and GPS technology

- The use of computers in the initial skill

Open thought: According to the data using GIS technology in risk assessment and planning of the audit process for the different ways in which they can contribute to the development of disaster risk reduction. When contracting with external experts to deal with the geographical information systems. When planning the audit process and identify the required requirements.

\section{MATERIALS AND METHODS}

The sampled population of the study consists of external auditors in the Iraqi environment represented by the financial clerks of the Federal Financial Control Bureau being one of the audit bodies which is responsible for carrying out the internal audit procedures. The aspect of the study, therefore, specializes on the financial sector in the health sector. A number of 15 questions were retrieved and analyzed. The questionnaire is divided into two parts: personal questions and general questions. 5-Likert scale was adopted for grading the responses: (5-fully agreed, 4-agreed, 3-neutral, 2-not agreed, 1-not fully agreed). The SPSS statistical program was used for the statistics, percentages and frequencies to describe the research sample and the arithmetic mean.

Sources of data and information collection: This study employed both deductive and inductive methods. The concept of the GIS system is presented and discussed using deductive approach. Additionally, the financial supervisors adopted the inductive approach to evaluating the professional opinion in accordance with the international auditing requirements in the field of environmental auditing and the use of GIS and the adoption of the relevant Arab and Foreign accounting literatures in order to develop the theoretical parts. For the current study in the foreign, Arab and local environments, the results of previous studies have been considered as reference studies.

Research plan: In accordance with disasters, crises and auditing standards, the second section deals with the concept of auditing and the modern techniques used for audit based on disasters and crises. The third section deals with the role of the GIS system in the disaster-based and crisis-based audit and the results of the survey.
Table 1: Characteristics of the study sample

\begin{tabular}{llr}
\hline Question & No. & Final (\%) \\
No./Question/Test & & \\
\hline $\mathbf{1}$ Scientific specialization & & 75 \\
Accounting & 15 & 25 \\
others & 5 & \\
$\mathbf{2}$ & & \\
Qualification & & \\
PHD & --- & 5 \\
Master & 1 & 75 \\
Legal auditor & 15 & 20 \\
Postgraduate & 4 & \\
Diplomax & & \\
$\mathbf{3}$ & & \\
Years of experience in & & 20 \\
practical field (Years) & & 10 \\
$<7$ & 4 & 50 \\
$7-12$ & 2 & 20 \\
$12-16$ & 10 & \\
$\geq 17$ & 4 & \\
\hline
\end{tabular}

Population of auditors in the Iraqi environment: A group of auditors (financial censors) working in the Federal Financial Control Bureau, specializing in work of the health sector is the selected sample for this study. They are specifically in the preparation of environmental reports. Through direct interviews, 20 questionnaires were distributed and 20 forms were retrieved and all (100\%) were valid for study.

Analysis of the characteristics of the study sample: In order to ensure that the answers could be relied upon and to enhance confidence in the results reached, the first part of the questionnaire included a set of data on the characteristics of individuals answering questionnaires as presented in Table 1.

In the accounting specialization, the sample of the study is $70 \%$ which indicates that the questionnaire focused on the individuals who practice the profession of controlling the accounts and environmental auditing in particular. Also, the study revealed that the various scientific qualifications that are carried out in the Financial Control Bureau (75\%). This indicates the possibility of relying on the results from the sample and the selected population with years of experience in the field of their work while accounting for $50 \%$ who have more than 17 inone year and $<12$ years.

\section{RESULTS AND DISCUSSION}

Wastewater as an environmental disaster in Iraq: For the past 10 years, an environmental decline has been witnessed by Iraq. Catastrophes, wars, conflicts and misguided policies have affected the environment in dealing with the environment from excesses and negligence from the spread of epidemics and diseases which has led to rapid leaps towards achieving a polluted environment suffering. 
Table 2: Classification of solid health care waste

\begin{tabular}{|c|c|c|}
\hline Types & Nature & Diagnosis and methods of conservation \\
\hline Normal solid waste & Harmless consists result of daily activities including paper, plastic and food scraps & Reservation in white bags (black) \\
\hline Radioactive waste & Harmful from the treatment of patients or excess of the need of medicines and expired & Keep in a metal box labeled with a beam \\
\hline Chemical waste & $\begin{array}{l}\text { Harmful produced by laboratories for chemical analysis, photocopying or } \\
\text { acidification and film waste }\end{array}$ & $\begin{array}{l}\text { Reservation in a plastic bag or container } \\
\text { (brown color) }\end{array}$ \\
\hline $\begin{array}{l}\text { Infectious medical } \\
\text { waste }\end{array}$ & $\begin{array}{l}\text { Harmful from blood, germ and viral testing, bandages, needles and contaminated } \\
\text { covers }\end{array}$ & Keep in plastic bags (yellow) \\
\hline
\end{tabular}

The Reports from the Ministry of Environment Department of Monitoring and Evaluation of Industrial Activities in 2010

Table 3: Types of liquid and gaseous health care waste

\begin{tabular}{|c|c|c|}
\hline Types & Nature & Diagnosis and methods of conservation \\
\hline $\begin{array}{l}\text { Waste liquid } \\
\text { sewage }\end{array}$ & $\begin{array}{l}\text { Harmful contain a high percentage of infectious diseases microbes of } \\
\text { bacteria, viruses and worms }\end{array}$ & Discharged it into public sewerage \\
\hline $\begin{array}{l}\text { Chemical } \\
\text { liquids }\end{array}$ & $\begin{array}{l}\text { The daily sterilization of parts, equipment, surfaces and floors, containing } \\
\text { organic and inorganic acids and alkalis }\end{array}$ & $\begin{array}{l}\text { Are discharged from public laboratories from analytical } \\
\text { laboratories and pathological laboratories without treatment }\end{array}$ \\
\hline $\begin{array}{l}\text { Pharmaceutical } \\
\text { liquid waste }\end{array}$ & $\begin{array}{l}1 \text { Dangerous harmful drugs are produced in tumor treatment sections and } \\
\text { contain antibiotics and toxic drugs }\end{array}$ & It is discharged into the public sewer \\
\hline $\begin{array}{l}\text { Remains of } \\
\text { minerals }\end{array}$ & $\begin{array}{l}\text { Hazardous harmful in small quantities with high toxicity such as mercury, } \\
\text { silver and lead from dental services centers and from the departments of } \\
\text { radiography or from the auxiliary technical departments in hospitals such } \\
\text { as movement and mechanical }\end{array}$ & It is discharged into the public sewer \\
\hline Invasive & $\begin{array}{l}\text { Hazardous hazards resulting from waste disposal in the holocaust } \\
\text { (damaged blood bags, damaged feed bags, ...) }\end{array}$ & $\begin{array}{l}\text { (Dioxin) which is composed of hundreds of chemicals and remains } \\
\text { for long periods of time in the environment because dioxin does } \\
\text { not react with oxygen and water and is not degraded by bacteria } \\
\text { and causes many diseases (cancer, infertility, diabetes, } \\
\text { immunodeficiency, skin problems), lung and others) }\end{array}$ \\
\hline
\end{tabular}

Preparation of the two researchers based on the Reports of the Ministry of Environment Department of Monitoring and Evaluation of Industrial Activities 2010

In the Iraqi environment, the problem of environmental sanitation is still a serious obstacleas organic pollution is generated which is often in the water. Therefore, the problem will be dealt with according to the health subject perspective of pollution.

\section{Contaminants of healthy subjects and species/waste of}

healthcare activities: Health-care waste is identified by the World Health Organization (WHO) to include all waste from health care institutions, research centers and laboratories or waste from secondary or discrete sources (WHO Morocco in 2007). The $25 \%$ of health-care waste (or health care waste hazard) is considered risky while the public waste should be treated by means of the disposal mechanism. To protect the environment and public health is the responsibility of hospitals and other care facilities and to treat and dispose of waste produced by pollutants.

Health-waste from hospitals, clinics, laboratories and centers of medical research centers and forensic medicine, health institutions and anatomy can be classified by nature as illustrated in Table 2 .

Table 3 clearly shows that, the waste of health care is considered to be harmful due to its very hazardous materials and different sources during the all stages of production, handling, storage and treatment. According to Fig. 1 the number of health institutions that perform municipal waste sorting on health care is negligible. From the survey, there is total number of 408 health institutions surveyed by the Ministry of Environment in Iraq while 332

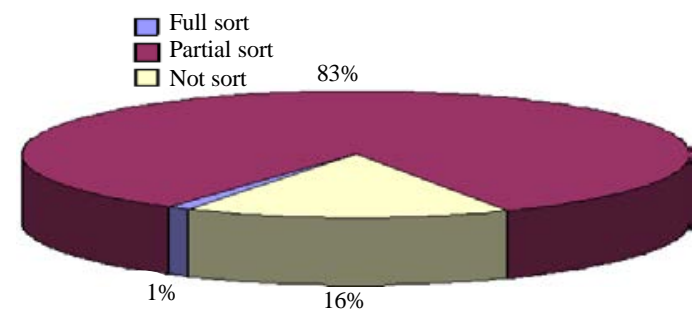

Fig. 1: The position of health institutions on the classification of waste of health care

health institutions are in care of the process of partial sorting of waste which constitutes $83 \%$ rate. There are 65 health institutions and establishment that do not produce any wastes from health care which constitutes $16 \%$ of the total number included.

In a number of private hospitals of $2291 \mathrm{~kg} /$ day and the rest of the health institutions of $1532 \mathrm{~kg} /$ day, the total number of hazardous waste is $15,770 \mathrm{~kg} /$ day. The total number of hazardous medical waste is $19800 \mathrm{~kg}$ and 72227 tons/year. Due to the lack of a balance of the weight in health waste, the figures are approximated.

Figure 2 shows the weight of the highly hazardous waste while Fig. 3 shows the weight of the usual less hazardous waste.

Additionally, the central incinerators in hospitals which are the most prevalent in Iraq are the methods adopted in the disposal of waste health care. These methods still failed due to inadequacy in the procedures such as the lack of a special balance of waste as provided 


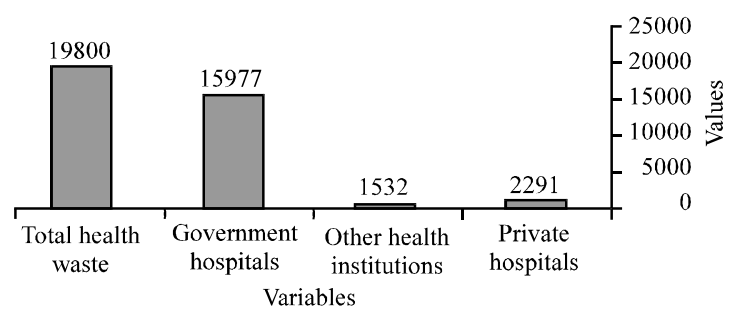

Fig. 2: The weight of the hazardous waste; Iraqi Ministry of Environment, Industrial Activities Monitoring and Evaluation Section, 2010

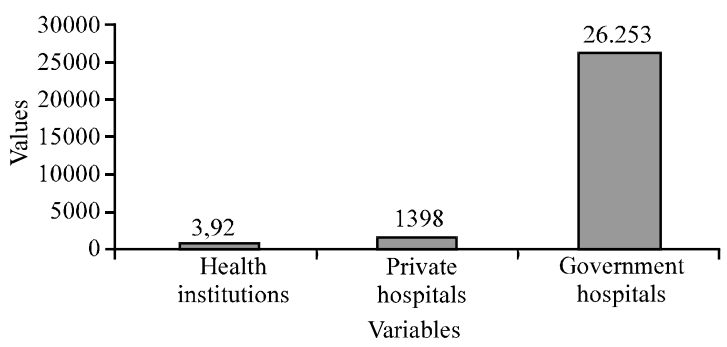

Fig. 3: The average weight of waste is less serious in health institutions $(000 \mathrm{~kg} /$ day $)$; Iraqi Ministry of Environment, Industrial Activities Monitoring and Evaluation Section, 2010

for environmental requirements in order to know the quantities in the rooms complete the burnings. The increase in quantities leads to complete combustion, thus, sending quantities to the landfill without incineration and the non-delivery of waste, especially the ones collected at night.

Excessive waste is caused due to waste arising from improper handling of burning products instead of being placed in special bags. Then, ash is collected by open carts and transported to the container complex in order to close an area. This leads to scattered and uncontrollable situation along the road leading to the containers and thus causing the spread of contaminants (Ministry of Environment and Technical Department in 2010). Table 4 illustrates the hospital's position on removal of waste from health care.

There is clear examination of the extent of the environmental disaster in the Iraqi environment regarding the depletion and waste of financial and human resources and the waste of health care professionals and its implications for the current and future stage of the Iraqi individual. Waste disposal is a problem of waste management which is the most serious environmental problems.

During the 17th International Conference of Supreme Audit Institutions held in Korea in 2001, the Supreme Audit Institutions (INTOSAI) reported the most serious environmental problems (INTOSAI., 2001).
Table 4: The position of the hospitals and the removal of the waste of the health care

\begin{tabular}{lll}
\hline Position of incinerators & Number of hospitals & Percentage \\
\hline
\end{tabular}

\begin{tabular}{lcc}
\hline Own incinerators & 106 & 57
\end{tabular}

$\begin{array}{lrr}\text { Do not have incinerators } & 80 & 43\end{array}$

$\begin{array}{lll}\text { Total } & 186 & 100\end{array}$

Ministry of Environment/2010

Second: The role of the federal audit office in environmental auditing based on disasters.

Health waste: One of the supreme oversight bodies in the Iraqi environment is the Federal Financial Control Bureau. The body works in accordance with the amended Law No. (13) for the year 2011. The working paper submitted by the Bureau to the INCOSAI Conference held in Cairo includes the definition of environmental auditing. The national and local authorities in the field of environmental protection and improvement work to measure the effect of the various organizational operations on the environment in accordance with the approved standards and the statement of cost whenever possible.

According to Article (11) of the Law of the Court, the control process shall be carried out in accordance with international and local rules and standards. The use of geospatial information in the audit of disaster management shall be used in accordance with the INTOSAI Standard (International Standard for Supreme Audit Institutions, 5540). At the time of environmental auditing, environmental auditing can be relied upon and adopted. The latter is limited to financial aspects.

According to International Standard 3000 (2007), INTOSAI describes performance auditing as an independent and efficient examination of projects and programs or governmental organizations in relation to the economy with a view to achieving improvements. Also, on the main reliance on performance auditing on some indicators related to performance. In the controlled bodies, the performance check is a topical examination of the policies, systems and management of operations. Federal Audit Bureau (2013) reported that for the purpose of detecting deviations and explaining their reasons on abuse and exploitation, it compares the achievement with the plans, results, rules and practice of the policy.

The work of the Federal Audit Bureau is limited to the traditional aspects of auditing. The Federal Audit Bureaudoes not employ new developments in the knowledge field or comply with the international standards of INTOSAI in the context of its work or environmental auditing procedures. Also, the Federal Audit Bureau does not respond to the observations contained in the report of the Financial Control Bureau.

The following observations of the waste of health care activities of one of the most important hospitals and 
the oldest in the Iraqi environment soft medicine include the specialized audit on environmental activity in the Department of Medicine for the period from January 2006-August 2007.

Disposal of wastes from the operating rooms and laboratories and contaminated materials such as antibiotics, gauze and cotton to be burned in a systemic incinerator and the pathological type were not available in the hospital in question due to non-compliance with the instructions issued by the Department of Environmental Protection.

Gas burning rather than light fuel and natural gas is favored to reduce gas pollution resulting from combustion. The production of gas-contaminated gases such as Carbon Monoxide (CO) and Sulfur Dioxide $\left(\mathrm{SO}_{2}\right)$ caused the operation of the incinerator.

The environment and workers are affected by the operation of the Holocaust card (1/6) production capacity due to the failure of the remaining parts and the accumulation of many waste without burning and sent to the landfill.

The incinerator stops working due to the lack of fuel, maintenance or frequent holidays and lack of a special balance as provided by the environmental instructions to know the quantities in the rooms of the incinerator to complete burning.

Non-compliance to the dispatch of medical waste to the incinerator, especially the waste collected at night, such as the hospital specialized in digestive system and liver and the hospital specialized in surgeries. As the combustion products are not placed in sealed bags where the ashes are collected by open-cast vehicles and transferred to the container complex outside the fence at the city Department of Medicine, this makes them uncontrollable.

Additionally, scattering of ash all the way to the containers can lead to the spread of contaminated materials associated with ash and materials for incomplete burning. Also, the location of the container complex is near to the residential areas with the situation of mixing of ordinary waste with large amounts of medical waste.

The role of GIS in environmental auditing on waste (healthcare): In terms of the suitability of sanitary landfill sites for health-care contaminants, the GIS shares and their geographic information outputs contribute to decision-making. For instance, appropriate location of health-care waste transfer stations should be done after incineration. Also, the selection of suitable sites and differentiation between locations according to pre-established criteria, the effectiveness of the land for the coverage, cost, distance, time of transport and secondary environmental impacts and size of the site through the production of maps of the proposed sites should be published on the websites (Kyessi and Mwakalinga, 2009).

One of the most important steps is the choice of the site and the process of disposal of waste health care which include many calculations and logistical decisions. For instance, may be the justification for the selection of the site is incorrect and not suitable for the effects of the environment and economic community. Therefore, the GIS will provide important information during the selection process (Saxena and Srivastava, 2011). In the field of identification of appropriate disposal sites and modes of transport especially in the use of GIS for the planning of the management of health care waste can be done through geographical analysis of the nature of the land and proximity to water bodies (Ghosh and Khan, 2014).

This study showed that the use of the GIS system and its advantages and ease of dealing and the low cost are due to the possibility of dealing with maps available on the internet that does not require participation in order to obtain the service as it is free (GPS). In the public sector, the support devices for the use of the system are usually available. Also, in the in the Iraqi environment, the elements of its adoptionare almost available from the equipment, receptors, expertise and scientific and practical qualifications.

As previously mentioned, the waste of health care is one of the environmental disasters afflicting the Iraqi environment at the current stage. The use of the GIS system should be in a proactive phase of the planning process. According to Guerrero et al. for the construction, separation, treatment, disposition, disposal and recycling the most important information related to the factors affecting the management of waste is information. The study concludes that this is done according to the following:

The stage of construction and separation: It requires information on the geographical areas, the type and size of the hospital as served by the hospital. In terms of the policies adopted by the senior management in the optimal use of financial resources, the approaches are adopted in the disposal of waste. The application of health economics and methods are approved in the separation of waste accordance with the types and guides of both local and global professional safety.

The treatment stage: As a basis for disposal of the waste of traditional healthcare providers (burners) or modern equipment (Shredding device), the stage where the external auditor needs to know the information about the type of infrastructure available in the country depends on 
Table 5: Results of measuring the contribution of the GIS system in improving environmental auditing

\begin{tabular}{lllcc}
\hline Question No. & Questions & Mean & Percentage & SD \\
\hline 1 & $\begin{array}{l}\text { GIS helps to support and support environmental audits } \\
2\end{array}$ & $\begin{array}{l}\text { The use of GIS at all stages of planning, design, risk assessment, } \\
\text { analysis and final report adds value to environmental auditing } \\
\text { The use of GIS by connecting GPS devices, Global Positioning System (GPS) } \\
\text { and satellite-based maps increases the quality of environmental auditing }\end{array}$ & 4.759 & 75.18 \\
& 4.233 & 82.66 & 0.875 \\
& & 4.682 & 9.786 \\
\hline
\end{tabular}

Table 6: Answers of the research sample on the available ingredients

\begin{tabular}{|c|c|c|c|c|}
\hline Question No & Questions & Mean & Percentage & $\mathrm{SD}$ \\
\hline 1 & I have knowledge of computer technology & 4.863 & 95.430 & 0.441 \\
\hline 2 & I have the ability to deal with GIS technology & 4.560 & 86.760 & 0.786 \\
\hline 3 & We have computers, equipment and support equipment to adopt GIS technology in our audit work & 4.441 & 83.670 & 0.861 \\
\hline 4 & We have the human, technical and infrastructure capabilities to use GIS in our audit work & 4.621 & 90.121 & 0.778 \\
\hline
\end{tabular}

the hospitals. Everytime waste is disposed of the standard of waste is applied from the type ofenvironmental evidence and instructions adopted in the methods of control and treatment of waste.

Phase of disposal: This is the stage where the auditor needs to know how to transfer the remnants of incinerators or shredding and sterilization devices and distances into the areas of housing, access the landfill (burial) and information on the above places.

According to Zacchia (2015), knowledge and evidence to prove the audit and a means to achieve the goals of auditing skillfully and professionally are provided by the implementation of the control activities in the field of solid waste management through some technical methods and interviews with the workers. In the same view, how to spend government funds (public money) are audited in the review of documents and inspection records and examination of reports from other sources such as databases and sites of various environmental statistics of international organizations. Thus, the success of the conduct of regulatory activities related to the environment and the improvements can be introduced (INTOSAI., 2001).

At the stage of planning the work of reviewing the solid waste management system, there is possibility of completing the audit tasksusing GIS and GPS. During construction, separation phases, collection, transport, means of transport, treatment, disposition or disposal, the most important information related to the factors that affect the management of solid waste should be studied.

Analysis of the results of the GIS contribution to the improvement of environmental audit reports: Table 5 presents the results of the environmental audit under GIS contribution to the improvement of the environmental audit reports after the respondent's answers to the questions contained in the second part of the questionnaire were discharged.
It is clear from Table 5 that the answers came in the direction of approval with an average of 4.682 and 94.46 that the quality of environmental auditing is increased with the use of GIS techniqueon an average value of 4,759 and $82.66(75.18 \%$ ) with an average mean (4.233). Thus, the application of GIS at all stages of planning for environmental auditing contributes to adding value to environmental auditing.

The results of the research sample answers regarding the availability of the main elements of the adoption of the GIS in environmental auditing by the environmental auditing team in the Iraqi environment.

In terms of the scientific and practical elements of the audit team, Table 6 presents the questionnaires were divided into subsections related to the elements available in the Iraqi environment and the available components of the basic equipment and support.

With an average score of 4.561 and 86.76 in the audit team, the analysis of the sample responses shows that 95.43 of the respondents possess technical knowledge using computers to deal with GIS technique (83.67) and an average of 4.441. To adopt the GIS system, there is possession of computers and equipment that support the work of GIS (90\%) with average value (4.621) according to what is submitted. Thus, the hypothesis is accepted.

\section{CONCLUSION}

The results of the study led to a number of conclusions: due to poor handling of waste healthcare, Iraq is suffering at the current stage of environmental disaster with the high rates of pollution.

Environmental auditing carried out by the external oversight bodies at the current stage is a traditional financial audit.

The leading role played by the GIS system is the employment of contemporary technologies for the purposes of environmental regulatory reformin providing benefits. The control is improved by reducing the waste 
of public money on the other hand through the optimal use of resources available by the facilities offered by the GIS system and benefits from the adoption.

In the Iraqi institutional environment, data available are presented for the adoption of the INTOSATI Standard (5540) and the use of the GIS system in terms of scientific and practical elements of the audit team with available components of basic support and equipment. Whether financial or human, the GIS system works to reduce the waste of economic resources.

\section{LIMITATIONS}

This study is limited to the aspect of waste of health care (solid and liquid) as produced by one of the types of solid waste in public and private hospitals in Baghdad governorate. It followed the same year in accordance with the information issued by the Iraqi Ministry of Environment and with the performance evaluation reports issued by the Federal Audit Bureau for 2010.

\section{RECOMMENDATIONS}

With the above conclusions, a number of suggestions are recommended, most importantly: the regulatory bodies should be invited to adopt the GIS system in environmental audits. The external regulatory bodies should be urged to adopt modern technologies to bring regulatory reforms in an environment characterized by many variables.

In auditing the aid or the amounts disbursed to some environmental disasters, the GIS system is one of the important technologies which have many benefits that can be employed such as in the case of IDP that can be considered as a future research study in the Iraqi environment.

\section{REFERENCES}

Ghosh, C.M. and M.A. Khan, 2014. GIS application in urban solid waste management: A case study of Dar es Salaam, Tanzania. J. Environ. Planner, 1: 1-19.

INTOSAI., 2001. INTOSAI working group on environmental control international court of control. International Organization of Supreme Audit Institutions, ýVienna, Austria.

INTOSAI., 2013. ISSAI 5540-Use of geospatial information in auditing disaster management and disaster-related aid. International Organization of Supreme Audit Institutions, International Organization of Supreme Audit Institutions, Vienna, Austria. ISSAI 5540-Use of geospatial information in auditing disaster management and disaster-related aid.

Kyessi, A. and V. Mwakalinga, 2009. GIS application in coordinating solid waste collection: The case of Sinza Neighbourhood in Kinondoni Municipality, Dar es Salaam City, Tanzania. Proceedings of the International Conference on FIG Working Week, May 3-8, 2009, Surveyors Key Role in Accelerated Development, Eilat, Israel, pp: 1-19.

Saxena, S. and R.K. Srivastava, 2011. GIS for site selection for hazardous waste landfills. IUP. J. Soil Water Sci., 4: 24-33. 